\title{
Family planning desires of older adults (50 years and over) in Botswana
}

\author{
Njoku Ola Ama ${ }^{\mathrm{a}, \mathrm{b} *}$ and John O Olaomi ${ }^{\mathrm{b}}$ \\ ${ }^{a}$ Department of Statistics, University of Botswana, Gaborone, Botswana \\ ${ }^{b}$ Department of Statistics, University of South Africa, Pretoria, South Africa \\ *Corresponding author, email: amano@mopipi.ub.bw; njoku52@gmail.com
}

Background: This study analysed the views of a stratified sample of 444 older adult women from selected health districts in Botswana on their family planning (FP) use, knowledge, accessibility and availability.

Methods: Four health districts (two rural and two urban) were purposively selected. The sample of 444 older adults was proportionally allocated to the districts. The snowball technique was used in identifying older adults from each district. Results: Contraceptive prevalence among the older adults is low (25. 2\%); ever used rate was $23.6 \%$, with unmet need as high as $75.2 \%$. The traditional methods are mainly used. Knowledge, availability and accessibility of the natural methods are high. The likelihood ratio test shows that age, educational status, marital status and employment jointly significantly predicts $(p<0.05)$ the use of FP.

Conclusion: Family planning programme developers and policy-makers should develop educational interventions that will be age specific and relevant to older adults.

Keywords: accessibility, availability, contraceptive, family planning, knowledge, older adults, use

\section{Introduction}

Family planning (FP) has been defined as a conscious decision by individuals or couples to choose for themselves when to start having children, how many children to have, how to space them or when to stop having children using (modern) contraception and/or natural methods. ${ }^{1}$ Having another baby within a year of giving birth can be physically traumatic. Breastfeeding two children who are closely spaced can affect the health of the mother, whereas proper spacing of children and having few children can help the woman take better care of the children and be able to work to improve the finances of the family or even further her education. ${ }^{2}$ It has been shown that parents who wait less than six months before conceiving again after a pregnancy have a $23 \%$ greater chance of having a baby born prematurely, and a $14 \%$ greater chance of having a child born with a birth defect. Additionally, women who have power over when they have their children are less likely to have abortions. ${ }^{3}$

At the launching of the Safe Motherhood Initiative in 1987 as a vertical programme, family planning was proposed as one of the four pillars, besides antenatal care, safe delivery and postnatal care; and proposed a strategic public health intervention to reduce maternal mortality in developing countries where $99 \%$ of global maternal deaths occur. ${ }^{4}$ The 1994 Cairo International Conference on Population and Development (ICPD) also reiterated the importance of family planning for improving women's health and directly linked the value of family planning to the reproductive health of individual women. ${ }^{5}$ It is now widely acknowledged that family planning reduces maternal mortality -both directly and indirectly. ${ }^{6}$

Family planning methods can be classified as either traditional/ natural or modern methods. The natural or traditional methods include abstinence, withdrawal, rhythm/calendar method and breastfeeding, while the modern methods include oral contraceptive pills, injectables (Depo-Provera), implants, emergency contraceptive pills, intrauterine contraceptive devices (IUD or IUCDs), the male and female condom and male and female sterilisation. $^{2}$

Studies ${ }^{7}$ have shown that 85 million pregnancies, representing $40 \%$ of all pregnancies in 2012, were unintended. Of these, $50 \%$ ended in abortion, $13 \%$ ended in miscarriage, and $38 \%$ resulted in an unplanned birth. A third of all pregnancies in sub-Saharan Africa are considered unintended (mistimed or unwanted) with the percentage varying by region. ${ }^{7}$ A little more than half $(55 \%)$ of all pregnancies in Southern Africa are unintended, while the figures are about $44 \%$ in Eastern Africa and roughly a quarter in Northern and Western Africa. ${ }^{7}$ A quarter of sexually active women in sub-Saharan Africa who report a desire to delay or limit childbearing are not using an effective method of family planning to meet these needs. ${ }^{8,9}$

Unmet need for contraception is also very high. ${ }^{10,11}$ In the developing countries, an estimated 222 million women would like to delay or stop childbearing but are not using any method of contraception. Reasons that have been given for not using contraception include the following: limited choice of methods limited access to contraception particularly among young people, poorer segments of populations, or unmarried people; fear or experience of side effects; cultural or religious opposition; poor quality of available services; and gender-based barriers. ${ }^{10,11}$ In Africa, 53\% of women of reproductive age have an unmet need for modern contraception; in Asia, and Latin America and the Caribbean-regions with relatively high contraceptive prevalence-the levels of unmet need are $21 \%$ and $22 \%$, respectively. ${ }^{10}$

\section{The need for family planning among older adults}

Women aged 50 years and over are often left out of any discussions or policies on the issues of family planning. Most of these women hardly think they can become pregnant because of infrequent sex, marital disruption, lack of a regular partner, 
menopausal status or their perception that they are infertile. ${ }^{12}$ They therefore do not consider that they have a need for contraceptives, either to prevent any unwanted pregnancy or for prevention of sexually transmitted diseases (STIs). Although women in this age group are less likely to get pregnant, they still require contraceptive information and services. Unfortunately, these messages are scarcely provided to them.

A Nigerian national survey showed that 6 in 10 women aged 35 and older reported that they had sex in the four-week period preceding the survey, a figure no different than younger women included in the survey. ${ }^{12,13}$ Even among men, a study by Holden et $a .^{14}$ on sexual activity, fertility and contraceptive use in middle-aged and older men in Australia, Telephone Survey (MATeS) found out that for men aged 50 years and over, the majority $(78.3 \%)$ were sexually active in the last 12 months before the study, with $37 \%$ of men aged 70 years still continuing sexual activity. Yet, family planning programmes are often focused only on teenagers, women seeking antenatal or postnatal care, women who bring their babies to the wellbaby clinic, and men. ${ }^{12-15}$ Much of the sexual and reproductive health services (including family planning) and service delivery target the women of child-bearing age (15-49 years) and sometimes men. There are hardly any special programmes/interventions that target the needs of the older adult women (50 years and above). Yet this group has serious family planning needs.

Studies have found that the sexual activity of women remains relatively stable as women move from young adulthood through mid-life and into the postmenopausal phase, with over two-thirds of women aged 39-50 (68\%) and 51-64 (65\%) reporting engaging in sexual intercourse at least once a week. ${ }^{16} \mathrm{~A}$ study of women aged $18-94^{17}$ found similar frequency of intercourse up to age 59 . While decreased libido has been reported as one menopause-related change, ${ }^{15,18}$ other women report an increase in sexual desire during and after menopause. ${ }^{19-20}$

Women need the protection that condoms provide against sexually transmitted diseases including HIV/AIDS. For those who are vulnerable, because of the lack of physical access, the lack of disability-related technical and human support, stigma and discrimination, family planning services are often inaccessible as well. Furthermore, with women living longer and healthier lives, and divorce a reality of life, many women and men in their fifties and above are finding new sexual partners later in life with increasing risk of contracting a sexually transmitted infection from a new partner. ${ }^{14}$ Figures suggest rates of STI infections have been on the increase among older people in the US and UK in recent years and there is a suggestion the same could be happening in Australia. Chlamydia, a common bacterial STI, is on the increase among all age groups in Australia and has more than doubled in those over 50 since 2005, going from 620 cases to 1446 in 2010. Gonorrhoea, another bacterial infection, has seen a slight increase in the over-50s, rising from 383 infections in 2005 to 562 in $2010 .^{21}$

While it is very important to focus resources on women of reproductive age, the public health services also need to ensure that the health needs of older women are adequately addressed. Begum and $\mathrm{Khan}^{22}$ revealed that about $31.4 \%$ of postmenopausal women suffered from obstetric-related gynaecological diseases.

Botswana is a country that is economically better off than its neighbours, with relatively good roads, solid communications networks and 24-hour hospitals fairly well distributed throughout the country. Although $90 \%$ of the people live within 5 kilometres of a health facility, currently there are serious barriers to comprehensive sexual and reproductive healthcare (including family planning). ${ }^{23}$ Sexual and reproductive health services (including family planning) in Botswana are fragmented and not comprehensive and while many of the projects that focus on HIV prevention and treatment are quality projects, there is little coordination between their efforts and the public health sector that provides family planning and maternal health. ${ }^{23}$

Understanding the family planning needs of older adult women is necessary for the development of appropriate medical and public health education, services and information targeted to an ageing population. In addition, exploring the knowledge, availability, accessibility and use of family planning issues in women as they age may provide insight into the development of education programmes better targeted to younger women. This is the crux of this paper. The good health of older women is very critical to the implementation of a healthcare programme, particularly for HIV/AIDS, as most of the care given to orphan children and HIV infected persons is provided by older adult women. There is need to bridge this gap in information.

The paper will determine the family planning desires of older adults, availability and accessibility of services, and factors that enhance/deter the utilisation of these services. The information provided will help policy and healthcare programme designers for family planning services to address issues that will improve the quality of life for older women and make them more relevant to society, while expanding family planning services.

\section{Conceptual framework for this study}

The study is guided by the framework on contraceptive use introduced by Ahmed. ${ }^{24}$ The decision to use contraceptive methods depends on three variables, motivation, attitude and access, as key determinants. In this study, there is a likelihood that some older adults may have reached their fertility desire before reaching age 50. For such a group, who might be in a relationship, contraceptives will be used to stop further pregnancy as well as STI infections including HIV. Yet, for others who may not have reached their fertility level but are in relationships and are sexually active, contraception might only be for the purposes of stopping contraction of STIs including HIV. A third group could be those who may not have reached their desired fertility but are unable to have children either because of menopausal conditions or due to other health problems, for whom contraceptive use might be to stop infection with STIs, especially if they are still in one-toone relationships. Given that health facilities are within about five kilometres from everyone and the road network is good, and the cost of accessing the services is insignificant (about 5 cents), one does not foresee much problem with older adults who are physically strong having sufficient motivation for contraceptive use and availing themselves of contraceptive services.

\section{Methods}

The study population was all women, 50 years and above, from four purposively selected districts: Gaborone, Selibe Phikwe (urban) and Barolong and Kweneng East (rural) in Botswana, to reduce the cost of the survey and for comparison of rural and urban differences. The 2001 projected Population and Housing Census gives the population of these women from the four districts as $22448 .^{25}$ 
Table 1: Sample size allocation of study sample to health districts

\begin{tabular}{lccc}
\hline $\begin{array}{l}\text { Health } \\
\text { district }\end{array}$ & $\begin{array}{c}\text { Population } \\
\text { size }\end{array}$ & $\begin{array}{c}\text { Proposed } \\
\text { sample size }\end{array}$ & $\begin{array}{c}\text { Achieved } \\
\text { sample size in } \\
\text { the study }\end{array}$ \\
\hline Gaborone & 7408 & 150 & 150 \\
$\begin{array}{l}\text { Selibe } \\
\text { Phikwe }\end{array}$ & 1983 & 40 & 45 \\
$\begin{array}{l}\text { Kweneng } \\
\text { East }\end{array}$ & 9676 & 196 & 207 \\
Barolong & 3381 & 68 & 42 \\
\hline Total & 22448 & 454 & 444 \\
\hline
\end{tabular}

The Creative Research System, ${ }^{26}$ a sample size calculator, gave a statistically adequate sample size as 378 . However, $20 \%$ of this sample size was added to account for those who were in the original sample but might be reluctant to participate or would not be available for interview. This gave a sample size of 454 older adult women for the study. This sample size of 454 was allocated to the selected districts using proportional allocation to size (Table 1). At the end of data collection, a total of 444 older adult women responded in completing the questionnaire. This gave a response rate of $98 \%$ (Table 1).

The snowball technique was used in identifying women in selected districts because of the sparse nature of the population and the difficulty in obtaining an updated sampling frame of older adult women. Snowball sampling is a non-probability method and may be used when the desired sample characteristic is rare, i.e. when it is extremely difficult or cost prohibitive to locate respondents in the study population because of factors such as maternal deaths. ${ }^{27-32}$

Only one instrument, a questionnaire, was used for the study. The questionnaire contained questions on the demographic characteristics of the older adult women, their sexual activities and needs, family planning needs, availability, access and limitations. The questionnaire was piloted at Tlokweng on a population similar to the one being studied for content, ambiguity, clarity, time for interview and administration of questionnaire before being used for the study. The questionnaire was administered to the respondents by trained research assistants who met the respondents in their homes or at work. The Setswana version (translated version of the questionnaire) was used in the case of those who could not understand English. The research assistants explained the purpose of the study to the respondents; assured them of confidentiality of information provided; and informed them that participation was not compulsory and there was no payment for participation. Those willing to participate signed a consent form before the interview began.

The instrument was reviewed by experts in public health and ageing, the University of Botswana ethical committee, the Ministry of Health Research and Ethical Committee and the District Health Management Teams in the study health districts before being used.

\section{Results}

\section{Socioeconomic characteristics of the older adult women}

Age of the women

A little over $50 \%$ of the women (53.2\%) were between 50 and 59 years, $27 \%$ were between 60 and 69 years, while $13.5 \%$ were between 70 and 79 years. About $1 \%$ were 90 years and above.

\section{Educational qualification}

Most of the women (42.8\%) had no educational qualification (no schooling) while $26.3 \%$ had a primary school certificate. A little more than $15 \%$ had either attempted secondary school or had a secondary school certificate. Close to $6 \%$ had either attempted a degree or had a university degree.

\section{Employment status}

In all, $35.1 \%$ of the women were unemployed but not seeking employment, $32 \%$ were employed, while $9 \%$ were unemployed but seeking employment. Close to $14 \%$ were housewives.

\section{Marital status}

Most of the women (32.9\%) were married while $27.9 \%$ were single (never married); $24.1 \%$ were widowed, $6.3 \%$ were cohabiting and $8.6 \%$ were divorced (Figure 1)

\section{Family planning desire of older adults}

Of the 444 respondents, $25.2 \%(n=112)$ indicated they still use family planning services, while $71.2 \%$ answered ' $\mathrm{No}^{\prime}$ and only $3.6 \%$ said they 'Don't know'.

\section{Knowledge of FP methods}

The older adults were asked to indicate which contraceptive methods they know from a list of all contraceptive methods provided. Knowledge, in this case, means that they have heard of a method to be used to avoid or delay pregnancy. ${ }^{33}$ The responses show that the top eight contraceptive methods known to the older adults were condom (86\%), abstinence (74\%), breastfeeding (72\%), IUD (60\%), combined oral contraceptives (54\%), pill (53\%), injectables (52\%), and withdrawal (38\%).

\section{Perceived availability of FP services in the healthcare services}

Availability was measured by the respondents' perceptions of the availability of FP advice and supplies, their perceived travel time, means of transport and distance to the nearest or preferred outlet, and their reported use of FP services. The respondents were then asked which FP planning methods were available to them in Botswana's healthcare system. The responses reveal the eight top FP services available to be condom (78\%), breastfeeding (72\%), abstinence (69\%), IUD (48\%), pills (47\%), injectables (43\%), combined oral contraceptives (43\%) and withdrawal (32\%).

\section{Accessibility of FP services}

The results show that the top eight FP services that were accessible to the older adult women were condom $(76 \%)$, breastfeeding (70\%), abstinence (68\%), pills (44\%), IUD (43\%), combined oral contraceptives $(40 \%)$, Injectables $(40 \%)$ and withdrawal (26\%).

\section{Use of FP planning methods}

Since some of the FP methods were accessible to the older adults and also available in the healthcare system of Botswana, and knowledge is good for some family planning methods (above 60\%), the study wanted to find out which of the methods they had used before (ever use) and which ones they are using now (current use) as knowledge does necessarily translate to usage of methods. ${ }^{34}$ Figure 2 shows the top eight FP methods that the older adults had used before. Breastfeeding (56\%) topped the list followed by condom (54\%), abstinence 


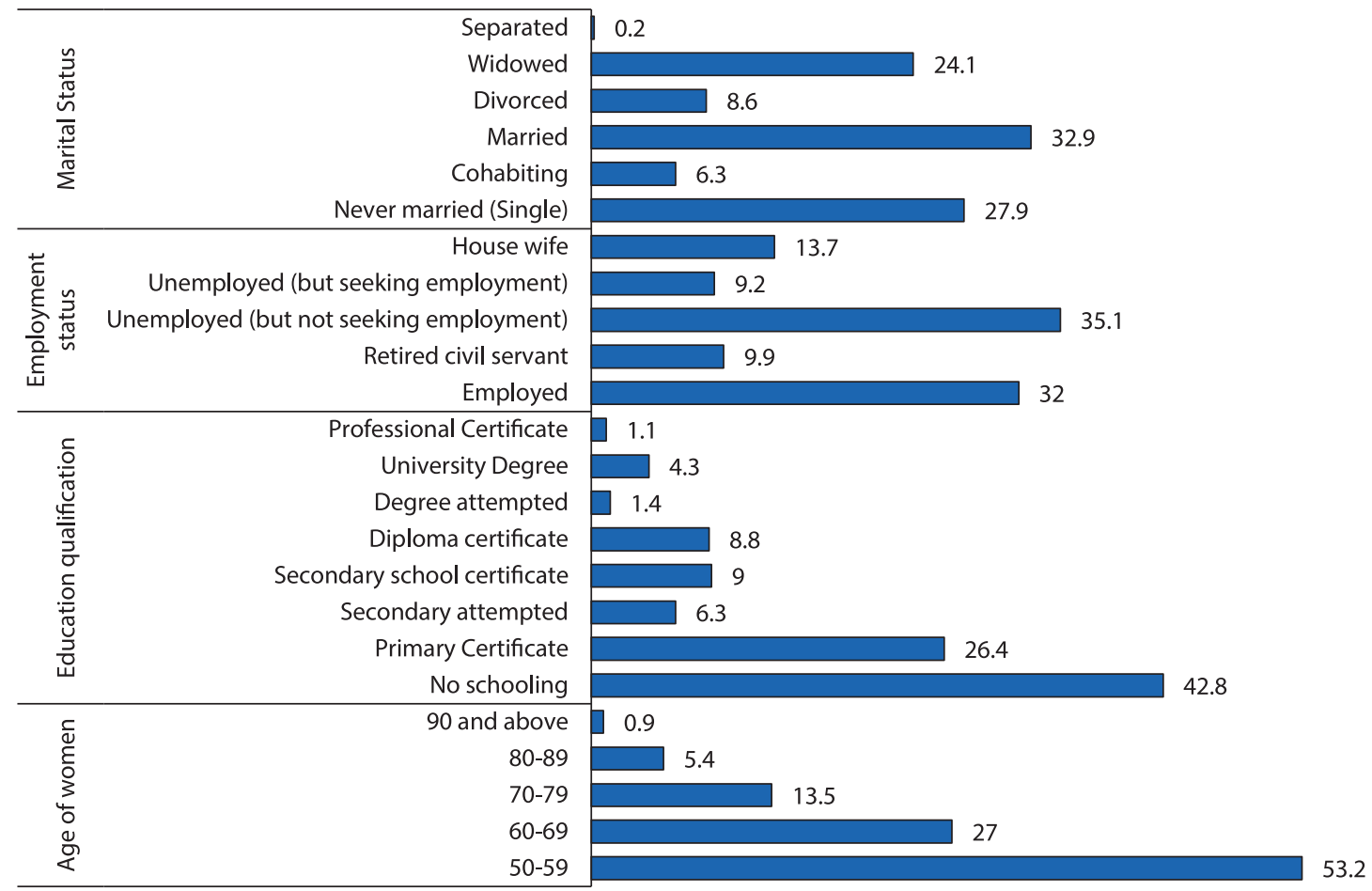

Figure 1. Characteristics of sampled older female adults.

(51\%), combined oral contraceptives (23\%) and pills (20\%). It is clear from these results that the majority of the older adults were mainly using natural contraceptive methods. The 'ever used' rate of contraceptive method was $23.6 \%$.

Regarding the methods the older adults were currently using (Figure 3 ), the results show that abstinence (55\%), condom $(41 \%)$ and breastfeeding (10\%) are currently being used. Thus they are seen to be consistently using natural or traditional methods more than modern methods. The current use rate is $34.7 \%$.

\section{Access to information on FP methods}

One way of improving usage of FP methods is through information on the availability and usefulness of the method, in terms of the side effects of using a contraceptive method and cost. The study asked the older adults whether they had full access to information regarding the quality of the family

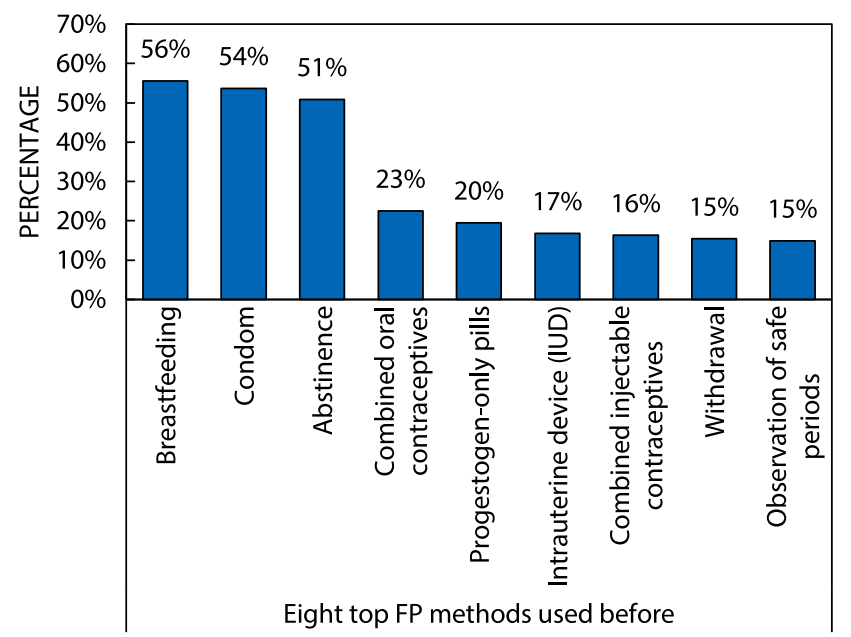

Figure 2: Family planning methods used beforehand. planning services they had either used before or are using now. The responses were coded as follows: $1=$ Not at all; $2=$ Sometimes (Below $50 \%$ of the time); $3=$ All the time (above $50 \%$ of the time); and $4=$ Don't know. The mean responses are given in Table 2 with the test of the significance of the means, measures of skewness and kurtosis for the responses. The mean values lie between 2.22 and 2.56, showing that the responses were between 'sometimes' and 'all the time'. The test of the hypothesis of whether the mean response was 2 revealed that the means were significantly different from 2 ( $p$ $<0.05$ ). This result is adequately supported by the coefficients of skewness, which are all close to zero, showing that most of the distributions are positively skewed and approximately symmetric (lying between -0.5 and 0.5 ).

\section{Unmet need for FP}

In order to determine the older adults' unmet need for FP, they were asked: 'Do you want to have another child?' Only 3.4\% $(n=$

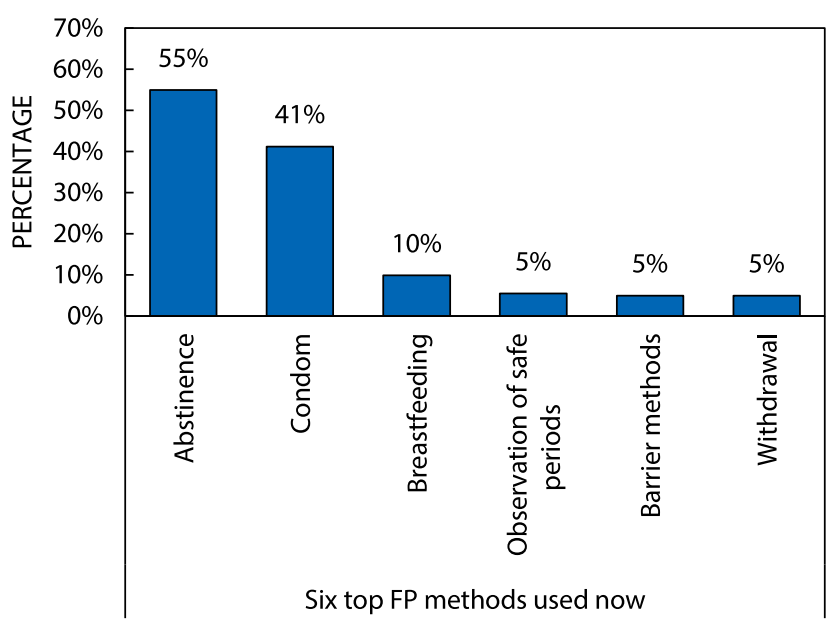

Figure 3: FP methods older adults use now. 
Table 2: Access to information on family planning methods

\begin{tabular}{|c|c|c|c|c|c|c|c|c|c|}
\hline \multirow[b]{2}{*}{$\begin{array}{l}\text { Have full access to information regarding } \\
\text { quality family planning services }\end{array}$} & \multirow[b]{2}{*}{$n$} & \multirow[b]{2}{*}{ Mean } & \multirow[b]{2}{*}{$\begin{array}{l}\text { Sig. }(2- \\
\text { tailed) }\end{array}$} & \multirow[b]{2}{*}{$\mathbf{t}$} & \multirow[b]{2}{*}{$\begin{array}{l}\text { Std. } \\
\text { error }\end{array}$} & \multicolumn{2}{|c|}{ Skewness } & \multicolumn{2}{|c|}{ Kurtosis } \\
\hline & & & & & & Statistic & $\begin{array}{l}\text { Std. } \\
\text { error }\end{array}$ & Statistic & $\begin{array}{l}\text { Std. } \\
\text { error }\end{array}$ \\
\hline Condom & 425 & 2.44 & 0 & 11.44 & 0.04 & -0.27 & 0.12 & -0.53 & 0.24 \\
\hline Intrauterine device (IUD) & 414 & 2.34 & 0 & 6.42 & 0.05 & 0.22 & 0.12 & -1.20 & 0.24 \\
\hline Combined oral contraceptives & 415 & 2.29 & 0 & 5.46 & 0.05 & 0.22 & 0.12 & -1.24 & 0.24 \\
\hline Progestogen-only pills & 411 & 2.39 & 0 & 7.25 & 0.05 & 0.14 & 0.12 & -1.27 & 0.24 \\
\hline Combined injectable contraceptives & 408 & 2.43 & 0 & 7.67 & 0.06 & 0.13 & 0.12 & -1.36 & 0.24 \\
\hline Female sterilisation & 403 & 2.22 & 0 & 3.64 & 0.06 & 0.33 & 0.12 & -1.47 & 0.24 \\
\hline Breastfeeding & 412 & 2.53 & 0 & 11.05 & 0.05 & -0.25 & 0.12 & -0.94 & 0.24 \\
\hline Barrier methods & 403 & 2.4 & 0 & 6.06 & 0.07 & 0.10 & 0.12 & -1.74 & 0.24 \\
\hline Sterilisation & 402 & 2.34 & 0 & 5.27 & 0.07 & 0.17 & 0.12 & -1.72 & 0.24 \\
\hline Emergency contraception & 396 & 2.27 & 0 & 3.99 & 0.07 & 0.28 & 0.12 & -1.76 & 0.25 \\
\hline Abstinence & 404 & 2.56 & 0 & 12.08 & 0.05 & -0.40 & 0.12 & -0.78 & 0.24 \\
\hline Withdrawal & 398 & 2.32 & 0 & 5.24 & 0.06 & 0.15 & 0.12 & -1.59 & 0.24 \\
\hline Observation of safe periods & 401 & 2.34 & 0 & 5.47 & 0.06 & 0.15 & 0.12 & -1.63 & 0.24 \\
\hline
\end{tabular}

15) answered 'Yes', while $93.4 \%(n=415)$ answered 'No' and $3.2 \%(n=14)$ said 'Don't know'. It is, therefore, expected that the $93.4 \%$ should be using some method to prevent further pregnancy. When this group were asked if they were using any method to prevent further pregnancy, $75.4 \%$ of them $(n=$ $314)$ stated that they were not using any methods. Only $24.6 \%$ ( $n=101$ ) were using some method, giving the level of unmet need for prevention of further pregnancy as $75.4 \%$.

\section{Relationship between use of FP and socioeconomic characteristics of the older adults}

The relationship between older adults' use of family planning methods to prevent pregnancy/STI infection and the age, marital status, educational status and employment status of respondents was established by fitting multinomial logistic regression ${ }^{35-36}$ models to the data with the outcome (dependent) variable 'Use family planning to prevent further pregnancy/STI infection'. The independent variables were: age, marital status, educational qualification and employment status, each coded as shown in Table 3.

The result of the test of significance of the parameters in the model using the Likelihood Ratio test (Table 4) shows that while educational qualification and marital status are not significant factors $(p>0.05)$, age and employment status are highly significant $(p<0.05)$.
The first model fitted in the analyses (Table 5) reveals for the older adults who responded 'Yes' to the question, 'Do you use FP to prevent pregnancy/STIs', compared with those whose response was 'Don't know', that those who are unemployed (but seeking employment) are overwhelmingly more likely to use FP than the housewives, whereas the employed, retired and unemployed but not seeking employment are less likely to use FP compared with the housewives. Those who are aged 50-59 years and 60-69 years are about 4.5 times and 2 times respectively more likely to use FP than those aged 90 years and above. The older adults who are single/cohabiting, married or divorced/separated are respectively 4.7, 3.9 and 3.6 times more likely to use FP services than the widowed. While the older adults who never had any schooling or completed primary education are 1.3 and 2.3 times, respectively, more likely to use FP than those who have a diploma or degree certificate, those who have a secondary education qualification are less likely to use FP than those who have diploma/degree certificates.

The second model, which represents the outcome of comparing the responses of the older adults who said 'No' to the question, are compared with those who responded 'Don't know'. The employed and retired older adults are less likely to use FP compared with housewives, while those who are unemployed but seeking employment are overwhelmingly more likely to use FP. Those who are unemployed but not seeking employment

Table 3: Description of variables for multinomial logistic regression analysis

\begin{tabular}{|c|c|c|}
\hline Dependent variable & $\begin{array}{l}\text { Use family planning to prevent } \\
\text { pregnancy }\end{array}$ & $1=$ No; $2=$ Yes; $3=$ Don't know \\
\hline \multirow[t]{3}{*}{ Independent Variables } & Age (completed years) & $1=50-59 ; 2=60-69 ; 3=70-79 ; 4=80-89 ; 5=90$ and above \\
\hline & Employment status & $\begin{array}{l}1=\text { Employed } \\
2=\text { Retired } \\
3=\text { Unemployed (but not seeking employment) } \\
4=\text { Unemployed (but seeking employment) } \\
5=\text { Housewife }\end{array}$ \\
\hline & Educational status & $\begin{array}{l}1=\text { No schooling } \\
2=\text { Primary certificate } \\
3=\text { Secondary certificate } \\
4=\text { Diploma and degree }\end{array}$ \\
\hline
\end{tabular}


Table 4: Multinomial logistic regression analysis tests

\begin{tabular}{|c|c|c|c|c|}
\hline \multicolumn{5}{|c|}{ Likelihood ratio tests } \\
\hline \multirow[b]{2}{*}{ Effect } & \multirow{2}{*}{$\begin{array}{c}\begin{array}{c}\text { Model fitting } \\
\text { criteria }\end{array} \\
-2 \text { log likelihood } \\
\text { of reduced model }\end{array}$} & \multicolumn{3}{|c|}{ Likelihood ratio tests } \\
\hline & & $\begin{array}{c}\text { Chi- } \\
\text { square }\end{array}$ & df & Sig. \\
\hline Intercept & 295.309 & 0 & 0 & . \\
\hline $\begin{array}{l}\text { Employment } \\
\text { status }\end{array}$ & 316.704 & 21.394 & 8 & 0.006 \\
\hline Age of women & 312.388 & 17.079 & 8 & 0.029 \\
\hline Marital status & 305.161 & 9.851 & 6 & 0.131 \\
\hline $\begin{array}{l}\text { Educational } \\
\text { Qualification }\end{array}$ & 304.417 & 9.108 & 6 & 0.168 \\
\hline
\end{tabular}

are 1.1 times more likely to use FP than the housewives. Differences in age do not significantly make any difference in usage, as those who are aged 50-59, 60-69, 70-79 and 80-89 are, respectively, 1.1 times, $1.02,1.04$ and 1.3 times as likely to use FP compared with those aged 90 years and above. The single/ cohabiting, married and divorced/separated women are, respectively, 3.9, 5.5 and 6 times more likely to use FP than the widowed. The results further show that while those who had no schooling are 3.4 times more likely to use FP than those who had degree/diploma certificates, the older adults who had completed primary education and those who had completed secondary education are, respectively, 4.5 and 2 times more likely to use FP than those who have a diploma certificate or degree for the purpose of either preventing further pregnancy or infection of STIs.

Table 5: Multinomial logistic regression model

\begin{tabular}{|c|c|c|c|c|c|}
\hline $\begin{array}{l}\text { Reference category } \\
=\text { Don't know }\end{array}$ & Effect & B & df & Sig. & $\operatorname{Exp}(B)$ \\
\hline \multirow[t]{19}{*}{ Yes } & Intercept & 19.012 & 1 & 0.994 & \\
\hline & Employed & -1.588 & 1 & 0.194 & 0.204 \\
\hline & Retired & -2.13 & 1 & 0.108 & 0.119 \\
\hline & Unemployed (but not seeking employment) & -1.479 & 1 & 0.232 & 0.228 \\
\hline & Unemployed (but seeking employment) & 14.382 & 1 & 0.995 & 1762244 \\
\hline & Housewife (reference category) & 0 & 0 & . & . \\
\hline & $50-59$ & -16.926 & 1 & 0.995 & 4.46 \\
\hline & $60-69$ & -17.738 & 1 & 0.995 & 1.98 \\
\hline & $70-79$ & -1.26 & 1 & 1 & 0.284 \\
\hline & $80-89$ & -1.822 & 1 & 0.156 & 0.162 \\
\hline & 90 and above (reference category) & 0 & 0 & . & . \\
\hline & Single/cohabiting & 1.538 & 1 & 0.056 & 4.657 \\
\hline & Married & 1.351 & 1 & 0.073 & 3.861 \\
\hline & Divorced/separated & 1.277 & 1 & 0.304 & 3.586 \\
\hline & Widowed (reference category) & 0 & 0 & . & . \\
\hline & No schooling & 0.228 & 1 & 0.801 & 1.256 \\
\hline & Primary certificate & 0.853 & 1 & 0.38 & 2.347 \\
\hline & Secondary certificate & -0.09 & 1 & 0.916 & 0.914 \\
\hline & Diploma and degree (reference category) & 0 & 0 & . & . \\
\hline \multirow[t]{19}{*}{ No } & Intercept & 17.099 & 1 & 0.995 & \\
\hline & Employed & -0.548 & 1 & 0.648 & 0.578 \\
\hline & Retired & -1.19 & 1 & 0.358 & 0.304 \\
\hline & Unemployed (but not seeking employment) & 0.093 & 1 & 0.939 & 1.097 \\
\hline & Unemployed (but seeking employment) & 15.28 & 1 & 0.994 & 4326402 \\
\hline & Housewife (reference category) & 0 & 0 & - & . \\
\hline & $50-59$ & -16.067 & 1 & 0.995 & 1.05 \\
\hline & $60-69$ & -16.097 & 1 & 0.995 & 1.02 \\
\hline & $70-79$ & 0.036 & 1 & 1 & 1.037 \\
\hline & $80-89$ & 0.287 & 1 & 1 & 1.332 \\
\hline & 90 and above (reference category) & 0 & 0 & . & . \\
\hline & Single/cohabiting & 1.369 & 1 & 0.075 & 3.93 \\
\hline & Married & 1.703 & 1 & 0.017 & 5.491 \\
\hline & Divorced/separated & 1.784 & 1 & 0.135 & 5.957 \\
\hline & Widowed (reference category) & 0 & 0 & . & . \\
\hline & No schooling & 1.235 & 1 & 0.158 & 3.439 \\
\hline & Primary certificate & 1.514 & 1 & 0.11 & 4.546 \\
\hline & Secondary certificate & 0.689 & 1 & 0.395 & 1.992 \\
\hline & Diploma and degree (reference category) & 0 & 0 & . & . \\
\hline
\end{tabular}


The likelihood ratio test of the significance of the parameters in the model shows that age, educational status, marital status and employment jointly significantly predict (chi-square $=67.731 ; p$ $<0.05$ ) the use of FP for prevention of pregnancy and STIs among the older adults studied.

\section{Summary and discussion of results}

This article set out with the objective of exploring older adults' needs for family planning methods, the availability, accessibility and use (before and now), and the level of unmet need for contraception. The socioeconomic characteristics of the surveyed older adults reveal that most of them (43.2\%) were without any schooling, and about one in every three were unemployed (35.4\%) and married (32.9\%). The huge number of participants with no schooling has an implication in understanding the available contraceptive methods as well as their usage, as most prescriptions are in English. This could have contributed to the low contraceptive use among the studied sample. A study by Ayoub $^{37}$ on the effects of women's schooling on contraceptive use and fertility in Tanzania found that more education is positively associated with contraceptive use. The relations become stronger with higher levels of schooling. Solanke ${ }^{38}$ also showed that maternal education was negatively related to non-use of contraceptives. As educational level improves, the proportion of non-users of family planning services reduces consistently. The author also showed that, at 40-44 years, maternal age was negatively associated with non-use of contraceptive, but at 45-49 years the relationship was positive. The results of this study also show that more than half of the older adults may have just barely had their menopause or could be having a delayed menopause. The use of FP at this stage is inevitable.

The study shows a contraceptive prevalence level of $25.2 \%$ among the older adults 50 years and above. This prevalence level is very much lower than the national contraceptive prevalence level of $40 \%{ }^{36}$ or $52.8 \%$ in 2008 reported in Botswana ${ }^{34}$ and $46 \%$ in $\mathrm{Kenya}^{35}$, although based on the percentage of women aged 15-49 years. This low level of contraceptive use is worrisome considering the fact that on a question on their attitude towards sex a good proportion of them (27.7\%) responded that they still enjoyed having sex with their partners while $10.3 \%$ indicated that they took renewed interest in sex after menopause. Carrol ${ }^{39}$ also reported that $23 \%$ of men and $13 \%$ of women older than 50 years indicated that their most recent sex was with a friend or new acquaintance. The chances of them being infected with STIs, if pregnancy is excluded, are definitely not zero. Therefore, some form of contraception is advocated for this group.

The level of unmet need for contraceptive use for older adults is, at $75.4 \%$, more than three times that for the younger women in the Kenya study ${ }^{34}$ and more than six times the worldwide value in 2015 , where $12 \%$ of married or in-union women are estimated to have had an unmet need for family planning ${ }^{40}$ The level is very much higher than the $22 \%$ in the least developed countries, many of which are in sub-Saharan Africa, which is also the region where unmet need was highest (24\%), and double the world average in 2015. It is true that many of the older adults are over menopausal age but, because many of them are still sexually active and continue to have sex, the high unmet need is likely to be for protection from STIs and should be of concern to healthcare practitioners and public health policy-makers.

The study shows that although knowledge of family planning (72\%) as well as contraceptive knowledge for most of the traditional methods, e.g. abstinence (74\%) and breastfeeding (72\%) and condom use (86\%) among the modern methods, was generally high ${ }^{41}$ only very few older adults have heard about other modern contraceptive methods. Access and availability of these three methods were equally high. Our conjecture is that it is not so much the availability of family planning methods but rather lack of knowledge of the methods that prevents use of FP services. For instance, almost half of the 6.3 million pregnancies in the United States are unintended, despite the availability of a wide variety of highly effective contraceptive methods. ${ }^{12}$ This gap in knowledge can, therefore, limit the choice of appropriate contraceptive methods. Since knowledge was measured by the older adults indicating that they have heard about the methods, the implication of the low level of knowledge of the modern methods is that dissemination of information regarding contraceptive methods among older adult women might be very poor or that the medium of communication of such information may not have been very effective or accessible to older adults. Poor sexual health knowledge has been identified as one of the key factors that place sexually active adolescents as well as older women at a higher risk for unplanned pregnancies as well as sexually transmitted diseases including HIV and AIDS. ${ }^{42}$ Advocates for youth have shown that while contraceptives methods are offered free of charge in government health facilities, the information on contraceptive use in general is not easily available in Botswana to young students. ${ }^{43}$ It is not unlikely that this might also apply to older adults. Comprehensive sexuality education, which is currently being provided for young people to prevent child marriages, unwanted teenage pregnancies, unsafe abortions, HIV infection and other sexually transmitted infections, ${ }^{44}$ is equally recommended for older adults to save them from pregnancyrelated health hazards including HIV and STI infection.

The response to the question on current use of family planning, which shows that abstinence (55\%), condom (41\%) and breastfeeding (10\%) were the three most popularly currently used contraceptives, is not unexpected as usage of any method largely depends on how much knowledge one has about it and possibly its side effects. This claim is confirmed by the findings of Okech et al., ${ }^{41}$ who asserted that women who had used hormonal IUD and the condom were more likely to have good knowledge of them. It is clear from the findings that the usage of these contraceptive methods was low, reflecting the menopausal status of most of the older adults. Ama and $\mathrm{Ngome}^{46}$ showed that almost half of older adults reached menopause between age 41 and 50 years, as did just a quarter between the ages of 51 and 60 years. However, small numbers of women attained menopause between ages 31 and 40 years (5.2\%) or at age 61 or later $(0.7 \%)$. The use of abstinence and condoms is likely to prevent sexual transmission of diseases including HIV and AIDS. It is therefore important that sexual health education for older adults be directed more towards knowledge of contraceptive methods and the side effects that will help them prevent infection with STIs including HIV and AIDS. Rolf and Nieschlag ${ }^{47}$ have shown that there is a rising divorce and remarriage rate, which prompts an increasing proportion of older men and women aged more than 50 years, who retain life-long fertility, to form new relationships with a desire to have an active sex life and, often, to have children. For this group, the sexual education should be towards methods to prevent further pregnancy as well as to prevent STIs.

Among the socioeconomic factors that influence use of contraceptives by older adults the findings reveal that age of the older adult women and their employment status are the significant 
predictors of contraceptive use, while marital status and education are not significant. These results are supported by Hailemariam and Haddis, ${ }^{48}$ who identified age, knowledge of family planning and respondent's work status as significant factor affecting unmet need for contraceptive use. However, older women who were married or divorced/separated were about five times more likely to use some family planning methods than the widowed, which might likely be as a result of these groups engaging in new relationships and becoming more sexually active (see Rolf and Nieschlag ${ }^{47}$ ).

\section{Limitations of the study}

This study relied on the opinions of older adults in reaching conclusions. The researchers have no controls over these views but relied purely on the excellent methodology and analyses of results, which are good enough to produce quality results to facilitate reliable conclusions. It is also true that application of the snowball techniques can lead to some bias when a particular peer group constitutes the reference. The study ensured sufficient diversification among the participants, thereby eliminating bias.

\section{Recommendation}

In the light of the findings in this study, it is recommended that concerted efforts by family planning programme developers and policy-makers to develop educational interventions which are age specific and relevant to older adults be vigorously pursued to increase knowledge of contraceptive methods and use. Considering also the physical and mental states of older adults, such programmes/services should consider services that can be taken to the homes of older adults.

Acknowledgement - The authors wish to thank the University of Botswana, Office of Research and Development for funding the original study from which this article emanated. All the research assistants and the co-researcher, Dr Enock Ngome, who was unavailable to participate in developing this article, are also acknowledged.

Disclosure statement - No potential conflict of interest was reported by the authors.

\section{References}

1. Ministry of Health. Family Planning Methods. n.d. [cited 2017 Sep 8]. Available from: https://www.k4health.org/sites/default/files/FP_ Flipchart_Clinical_Providers_Technical.pdf.

2. FHI360. Facts for family planning. Durham (NC): HI360/ Communication. for Change Project; 2013; [cited 2017 Sep 9]. Available from: https://www.fphandbook.org/sites/default/files/ factsforfamilyplanning_0.pdf.

3. Mullins T. Why is family planning important? Livestrong.com., 2010. [cited 2017 Sep 22] Available from: http://www.livestrong.com/ article/72185-importance-family-planning/.

4. Ahmed S, Li Q, Liu L, et al. Maternal deaths averted by contraceptive use: an analysis of 172 countries. Lancet. 2012;380(9837):111-25.

5. AbouZahr C. Some thoughts on ICPD+5. Bull World Health Organ. 1999;77(9):767-70.

6. Stover J, Ross J. How increased contraceptive use has reduced maternal mortality. Maternal Child Health J. 2010;14(5):687-95.

7. Sedgh $G$, Singh $S$, Hussain R. Intended and unintended pregnancies worldwide in 2012 and recent trends. Stud Fam Plan. 2014;45(3):30114.

8. Bongaarts J. The impact of family planning programs on unmet need and demand for contraception. Stud Fam Plan. 2014;45(2):247-62.

9. Speizer IS, Lance P. Fertility desires, family planning use and pregnancy experience: longitudinal examination of urban areas in three
African countries. BMC Pregnancy Childbirth. 2015;15:294. doi 10. 1186/s12884-015-0729-3.

10. Republic of South Africa. I choose my protection: family planning facts. Department of Health, Republic of South Africa; 2014.

11. WHO. Family planning/Contraception, 2017 [cited 2017 Sep 12]. Available from: http://www.who.int/mediacentre/factsheets/fs351/ en/.

12. OlaOlorun F. Contraceptive Needs of Older Nigerian Women Are Neglected. Population Reference Bureau, 2013. [cited 2017 Sep 7]. Available from: http://www.prb.org/Publications/Articles/2013/ contraception-nigerian-women.aspx.

13. Nigeria National Population Commission and ICF International. Nigeria demographic and health survey 2008. Calverton (MD): ICF International; 2009.

14. Holden CA, McLachlan Rl, Cumming R, et al. Sexual activity, fertility and contraceptive use in middle-aged and older men: Men in Australia, telephone survey (MATeS). Hum Reprod. 2005;20 (12):3429-34.

15. Dennerstein L, Dudley E, Burger H. Are changes in sexual functioning during midlife due to aging or menopause? Fertil. Steril.. 2001;76 (3):456-60.

16. Janus SS, Janus $\mathrm{CL}$. The janus report on sexual behaviour. New York: John Wiley \& Sons; 1993.

17. Patel D, Gillespie B, Foxman B. Sexual behavior of older women: results of a random digit-dialing survey of 2000 women in the United States. Sex Transm Dis. 2003;30(3):216-20.

18. Reddish S. Loss of libido in menopausal women: management issues. Aust Fam Physician. 2002;31(5):427-32.

19. Koster A. Change-of-lifeanticipations,attitudesandexperiencesamongmiddle-aged danish women. Health Care Women Int. 1991;12 (1):1-13.

20. Koster A, Garde K. Sexual desire and menopausal development. A prospective study of danish women born in 1936. Maturitas. 1993;16(1):49-60.

21. Pogson J. Chlamydia at $50 \ldots$ Could it be you? ABC Health and Wellbeing, 2011. [cited 2017 Sep 12]. Available from: http://www. abc.net.au/health/thepulse/stories/2011/08/25/3299985.htm.

22. Begum A, Khan HT. Obstetric related residual morbidities among the women in Bangladesh. J Prev Soc Med. 1999;18(1):22-29.

23. Centre for Health and Gender Equity. The Case for comprehensive: Botswana. The Importance of Comprehensive, Rights-Based Approaches to Sexual and Reproductive Health. Countryprofile. 2009. [cited 2017 September 5]. Available from http://www.gende rhealth.org/files/uploads/change/publications/botswanacasestudy. pdf.

24. Ahmed B. Determinants of contraceptive Use in rural Bangladesh: The demand for children, supply of children, and costs of fertility regulation. Demography. Aug., 1987;24(3):361-73.

25. Central Statistics Office (CSO). The 2001 projected population and housing census. Gaborone: The Government Printers; 2011.

26. Creative Research Systems The Survey Systems: Sample Size Calculator. (2012). Available from: https://www.surveysystem.com/ sscalc.htm.

27. Singh P, Pandey A, Aggarwal A. . house-to-house survey vs.snowball technique for capturing maternal deaths in India:A search for a cost effective method Indian. J Med Res. 2007;125:550-6.

28. Vogt WP. Dictionary of statistics and methodology: A Non technical guide for the social sciences. London: Sage; 1999.

29. McNamara RP. The times square hustler: male prostitution in New York city. Westport: Praeger; 1994.

30. Griffiths P, Gossop M, Powis B, et al. Reaching hidden populations of drug users by privileged access interviewers: methodological and practical issues. Addiction. 1993;88:1617-26.

31. Sudman S, Freeman $\mathrm{H}$. The use of network sampling for locating the seriously ill. Med Care. 1988;26:992-9.

32. Snijders T. Estimation on the basis of snowball samples: how to weight? Bull Methodol Sociol. 1992;36:59-70.

33. Rutenberg N, Ayad M, Ochoa LH, et al. Knowledge and Use of contraception. demograhic and health survey comparative studies No. 6. Columbia (MD): Institute for Resource Develpoment/Macro International InC.; 1991; [cited 2017 Sep 24]. Available from: https:// dhsprogram.com/pubs/pdf/CS6/CS6.pdf. 
34. World Bank. Reproductive health at a glance: Botswana, 2011. Available from: http://siteresources.worldbank.org/INTPRH/Resourc es/376374-1282255445143/Botswana52411 web.pdf.

35. Starkweather J, Moske AK. nd. Multinomial logistic regression. [cited 2018 March 25] Available from: https://it.unt.edu/sites/default/files/ mlr_jds_aug2011.pdf.

36. Schwab JA. Multinomial logistic regression: Basic relationships and complete problems, 2002. [cited 2018 April 15], Available from: http://www.utexas.edu/courses/schwab/sw388r7/SolvingProblems/.

37. Ayoub AS. Effects of women's schooling on contraceptive Use and fertility in Tanzania. Afr Popul Stud. 2004;19(2):139-57.

38. Solanke BL. Factors influencing contraceptive use and non-use among women of advanced reproductive age in Nigeria. journal of health. Popul Nutr. 2017;36:1-14. https://doi.org/10.1186/s41043016-0077-6

39. Carrol JL. Sexuality now embracing diversity 4e. Wadswork Cengage Learning, University of Hartford; 2011.

40. United Nations, Department of Economic and Social Affairs, Population Division. Trends in Contraceptive Use Worldwide 2015 (ST/ESA/SER.A/349).

41. Okech TC, Wawire NW, Mburu TM. Contraceptive Use among women of reproductive Age in Kenya's city slums. Int J Business Soc Sci. 2011;2(1):22-43.
42. Williamson LM, Parkes A, Wight D, et al. Limits to modern contraceptive use among young women in developing countries: a systematic review of qualitative research. Reprod Health. 2009;6:3. https://doi. org/10.1186/1742-4755-6-3

43. Advocates for Youth. Youth Reproductive and Sexual Health in Botswana; 2009. [cited 2010 Oct 16 October]. www.advocates foryouth.org.

44. UNFPA. (n.d). Sexual and reproductive health. Available from: http:// botswana.unfpa.org/topics/sexual-reproductive-health-7.

45. Gosavi A, Ma Y, Wong $H$, et al. Knowledge and factors determining choice of contraception among Singaporean women. Singapore Med J. 2016;57(11):610-5. https://doi.org/10.11622/smedj.2015181.

46. Ama NO, Ngome E. Menopausal perceptions and experiences of older women from selected sites in Botswana. Adv Sexual Med. 2013;3(3). https://doi.org/10.4236/asm.2013.33009.

47. Rolf C, Nieschlag E. Chapter 21: The aging male. In: Nieschlag E, Behre $\mathrm{HM}$, editor. Andrology: male reproductive health and dysfunction. Berlin: Springer-Verlag; 2001. p. 419-32.

48. Hailemariam A, Haddis F. Factors affecting unmet need for family planning in southern nations, nationalities and peoples region, Ethiopia. Ethiop J Health Sci. 2011;21(2):77-89.

Received: 23-07-2018 Accepted: 28-09-2018 